\title{
JENSEN-TYPE INEQUALITIES AND THEIR APPLICATIONS
}

\section{Dinh Thanh DuC and NGuyen NGOC HuE}

Abstract. In the present paper, we establish some entirely new Jensen-type discrete and integral inequalities. As applications of these results, we strengthen the well-known majorization theorem of Hardy, Littlewood and Pólya, and we also give a generalization of Andersson's inequality.

Mathematics subject classification (2010): 26D15, 26A51.

Keywords and phrases: Jensen's inequality, Jensen-type inequality, refinement, reverse, generalization.

\section{REFERENCES}

[1] B. J. Andersson, An inequality for convex functions, Nordisk Mat. Tidskr. 6 (1958), 25-26.

[2] M. J. Cloud And B. C. DRAChman, Inequalities with Applications to Engineering, Springer, 1998.

[3] P. W. DAY, Decreasing rearrangements and doubly stochastic operators, Trans. Amer. Math. Soc. 178 (1973), 383-392.

[4] S. S. DRAGOMIR, Integral inequalities for convex functions and applications for divergence measures, Miskolc Math. Notes 17 (2016), no. 1, 151-169.

[5] S. S. DRAGOMIR, Some reverses of the Jensen inequality with applications, Bull. Aust. Math. Soc. 87 (2013), no. 2, 177-194.

[6] A. M. FINK, Andersson's inequality, Math. Inequal. Appl. 6 (2003), no. 2, 241-245.

[7] G. H. Hardy, J. E. Littlewood and G. Pólya, Inequalities, Cambridge Univ. Press, Cambridge, 1934.

[8] J. M. Hot AND Y. SEO, An interpolation of Jensen's inequality and its applications to mean inequalities, J. Math. Inequal. 12 (2018), no. 2, 303-313.

[9] M. A. Khan, G. A. Khan, T. Ali, A. Kilicman, On the refinement of Jensen's inequality, Appl. Math. Comput. 262 (2015), 128-135.

[10] G. G. Lorentz, Bernstein polynomials, Second edition, Chelsea Publishing Co., New York, 1986.

[11] G. LU, New refinements of Jensen's inequality and entropy upper bounds, J. Math. Inequal. 12 (2018), no. $2,403-421$.

[12] A. M. Mercer, A generalization of Andersson's inequality, J. Inequal. Pure Appl. Math. 6 (2005), no. 2, art. 57.

[13] J. E. PEČARIĆ, On the Ostrowski generalization of Čebyšev's inequality, J. Math. Anal. Appl. 102 (1984), no. 2, 479-487.

[14] M. S ABABHEH, Improved Jensen's inequality, Math. Inequal. Appl. 20 (2017), no. 2, 389-403. 